\title{
Preparation and characterization of bentonite nanocomposites via sol-gel process
}

\author{
Celeste M. Legarto ${ }^{1} \cdot$ A. Scian ${ }^{1,2} \cdot$ M. B. Lombardi ${ }^{1,2}$
}

(C) Springer Nature Switzerland AG 2019

\begin{abstract}
Different nanocomposites silica-resin based were prepared and characterized in order to achieve a porous monolith that contains bentonite and allows the flow of aqueous systems. The bentonite used to prepare the nanocomposites was a good adsorbent for various molecules in aqueous media in stirred tank reactor. But the challenge was the obtention of porous bentonite composite columns for industrial applications. The primary composite, silica-resin, was prepared by the sol-gel precursor mixture of the tetraethylorthosilicate (TEOS) and a phenolic resin, made up the gel which is then dried and cured at $180^{\circ} \mathrm{C}$. Bentonite was added to the precursor mixture obtaining the, silica-resin-bentonite composite, and also other potencial adsorbent, carbon, was added obtaining the silica-resin-bentonite-carbon composite. The different composites were mineralogical and structurally evaluated by X-ray diffraction, Infrared spectroscopy with Fourier transform, Differential thermal analyses and thermogravimetric analyses. The textural characterization was performed by Adsorption of nitrogen (Sg-BET), Mercury intrusion porosimetry and Scanning electron microscopy. The comparison of the characteristics and properties between the composites evidenced that the addition of bentonite modify the solgel process and interferes in the composite cured process, so that, modify the mesoporosity and macroporosity of the composite. But, there is a maximum clay limit to obtain an homogeneous monolith. The addition of carbon decreases the porosity of the composite to a greater extent when the granulometry is greater.
\end{abstract}

Keywords Adsorbent material · Nanoporous material $\cdot$ Silica-resin composite $\cdot$ Silica-resin-bentonite composite $\cdot$ Silicaresin-bentonite-carbon composite

\section{Introduction}

The synthesis of materials with nanostructures presents a great scientific interest for its technological applications such as fluid filter, organic molecules and macromolecules adsorbent, catalyst support, and many others [1].

Bentonites are clay minerals, formed mainly by smectitic minerals in the form of laminar silicates. In these minerals, its small size of particle, less than $4 \mu \mathrm{m}$ [2], generates a large specific surface area, and the presence of charge in the surfaces gives particular physico-chemical properties that allow to attract substances, for example from the solution in aqueous medium. That is why they are widely used as adsorbents of toxic compounds, among other important applications [3-6]. The one used in this work was tested in stirred tank reactor with organic and toxic molecules in aqueous media obtaining promising results [7-9].

It is also widely known the use of commercial carbon, as an adsorbent agent of contaminants in solution [10-12].

Even though many works refer to the formation of mesoporous siliceous compounds generated by the

Electronic supplementary material The online version of this article (https://doi.org/10.1007/s42452-019-0801-0) contains supplementary material, which is available to authorized users.

Celeste M. Legarto, celestelegarto@cetmic.unlp.edu.ar | ${ }^{1}$ CETMIC (CIC-CONICET), La Plata, Buenos Aires, Argentina. ${ }^{2}$ Facultad de Ciencias Exactas, Universidad Nacional de La Plata, La Plata, Argentina. 
gelification of TEOS in the presence of different surfactants under various experimental conditions [13-15].

In this work, different nanocomposites Silica-resin based were prepared and characterized in order to achieve a porous monolith where bentonite maintain its adsorbing capacity but allows the flow of aqueous systems in order to be applied for water treatments. It was prepared a composite material from the gelification of TEOS with a commercial phenolic resin, which was dried and cured at $180^{\circ} \mathrm{C}$ in order to get a network which we call primary composite (Silica-resin composite). Also, mixtures with the precursors of the primary composite and adsorbents as bentonite and carbon (two different granulometries), were prepared followed by drying and curing, getting Silica-resin-bentonite and Silica-resin-bentonite-carbon composites respectively. These, were characterized and evaluated mineralogical and structurally by $X$-ray diffraction (XRD), Infrared spectroscopy with Fourier transform (FTIR), Differential thermal analyses (DTA) and Thermogravimetric analyses (TGA). The textural characterization was performed by Adsorption of nitrogen (Sg-BET), Mercury intrusion porosimetry and Scanning electron microscopy (SEM).

\section{Methods}

\subsection{Materials}

TEOS is an organometallic compound $\left(\mathrm{Si}\left(\mathrm{CH}_{3} \mathrm{CH}_{2} \mathrm{O}\right)_{4}\right)$ which is hydrolyzed by mixing it with water and with a solvent such as alcohol, leading to the formation of a polymer gel with -Si-O-Si- bonds. Due to the polymerization process a three-dimensional reticulation is formed leading to the formation of a solid frame that traps water molecules and other compounds present. The TEOS used (SILBOND 40-AKZO Chemicals) is a mixture of partially hydrolyzed monomer, dimer, trimer, high polymers and cyclic polisilicates. The average chain length is approximately 5 units -Si-O-Si-.

The organic co-gelling used is a commercial liquid resin phenol-formaldehyde: RL 43003 (ATANOR S.A. Argentina).

The bentonite used (A), from the Northern Patagonia Argentina, is $97.4 \%$ montmorillonite, described in previous publications $[16,17]$. In order to carry out the mixtures, bentonite was dried at $60^{\circ} \mathrm{C}$ until constant weight.

The carbon used is a commercial one, being the majority phase graphite and whose porosity was evaluated by the mentioned techniques.

\subsection{Preparation of the composites}

The TEOS and resin was used as received while bentonite and carbon were dried at $60^{\circ} \mathrm{C}$ until constant weight. The primary composite $(C)$ was prepared by mixing TEOS and resin with magnetic stirrer until obtaining an emulsion, adding commercial ethanol (96\%) and destilled water gradually reaching an amber colour translucent liquid. Other composites were prepared following the steps of $C$ with the addition of bentonite and carbon. For composite $(C-A)$ bentonite was added in a suspension of $70 \%$ water and $30 \%$ ethanol. The carbon was milled and sieved obtaining two fractions 150-106 $\mu \mathrm{m}(-100+140$ mesh, ASTM series) and $106 \mu \mathrm{m}(-140$ mesh, ASTM series) with which composites $(C-A C-100+140)$ and $(C-A c-140)$ were prepared respectively.

Table 1 presents the composition of the composites prepared.

The liquid pre-gel was placed in covered cylindrical molds to achieve the gelation at room temperature without evaporation of the solvents (alcohol and water). After $24 \mathrm{~h}$, the mixture gelled and the molds were uncovered allowing evaporation of the solvents. Once, unmoulded, were dried at room temperature and then in an oven at $60^{\circ} \mathrm{C}$ for $24 \mathrm{~h}$ and finally cured at $10^{\circ} \mathrm{C} / \mathrm{h}$ up to $180^{\circ} \mathrm{C}$. At this temperature resin polymerizes and solidifies. So that, if the unstable solid post-gel is not cured, resin lixiviates when an aqueous system flows through it. Also, the percentage of water within the material is very high within the first $24 \mathrm{~h}$ and this would affect the availability of clay for adsorption.

\subsection{Characterization}

The composites obtained were evaluated mineralogical and structurally by X-ray diffraction (XRD) using a Philips PW-3710 with Cu-Ka radiation $(\lambda=0,154 \mathrm{~nm})$ at $40 \mathrm{kV}$ and $35 \mathrm{~mA}$ and sweep range ${ }^{\circ} 2 \theta$ ranging from $3^{\circ}$ to $70^{\circ}$. Infrared spectroscopy with Fourier transform (FTIR) studies
Table 1 Composition of the different composites

\begin{tabular}{lllllll}
\hline Composite & Resin $(\mathrm{g})$ & Teos $(\mathrm{ml})$ & Ethanol $(\mathrm{ml})$ & Water $(\mathrm{ml})$ & Bentonite $(\mathrm{mg})$ & Carbon $(\mathrm{mg})$ \\
\hline C & 10 & 20 & $23+3$ & 7 & No & No \\
C-A & 10 & 20 & $23+3$ & 7 & 100 & No \\
C-Ac-100+140 & 10 & 20 & $23+3$ & 7 & 100 & 50 \\
C-Ac-140 & 10 & 20 & $23+3$ & 7 & 100 & 50 \\
\hline
\end{tabular}


were performed by Bruker vertex 70 transmission spectra were obtained in the area $4000-400 \mathrm{~cm}^{-1}$. Differential thermal analyses (DTA) and Thermogravimetric analyses (TGA), both thermal analyses were carried out simultaneously at a $10^{\circ} \mathrm{C} / \mathrm{min}$ heating rate in air atmosphere up to $1000^{\circ} \mathrm{C}$ using alumina as reference (RigakuEvo plus II, Japan). The textural characterization was performed by the adsorption isotherms of $\mathrm{N}_{2}(\mathrm{Sg}-\mathrm{BET})$ in a Micromeritics ASAP 2020 analyser. Mercury intrusion porosimetry by $\mathrm{Hg}$ intrusion was determined by a Porosimeter Pascal-Thermo Fisher 440 and 140 . The scanning electron microscopy (SEM), was obtained with a JEOL CM-600 Neo Scope.

\section{Results and discussion}

\subsection{X-ray diffraction}

The diffractograms for the composites (cured at $180^{\circ} \mathrm{C}$ ) and bentonite (dried at $60^{\circ} \mathrm{C}$ and also at $180^{\circ} \mathrm{C}$ ) are shown in Fig. 1, in $\mathrm{A}$ there are reflections of the pure minerals, montmorillonite and minority minerals such as gypsum, quartz, and feldspar. Reflection d(001), characteristic of the interlamellar spacing of montmorillonite, is located in the position $7.8^{\circ} 2 \theta\left(11.2 \AA\right.$ A ) for sample A dried at $60^{\circ} \mathrm{C}$ which is the humidity condition when composites with bentonite were prepared. Sample $A$ when drying at $180^{\circ} \mathrm{C}(\mathrm{A} 180)$, presents the reflection $d(001)$ shifted to $8.1^{\circ} 2 \theta(11.0 \AA)$ which indicates the loss of water in the interlamellar spacing [18].

In the XRD patterns of the different composites, only two bands are observed, indicating low crystallinity. From

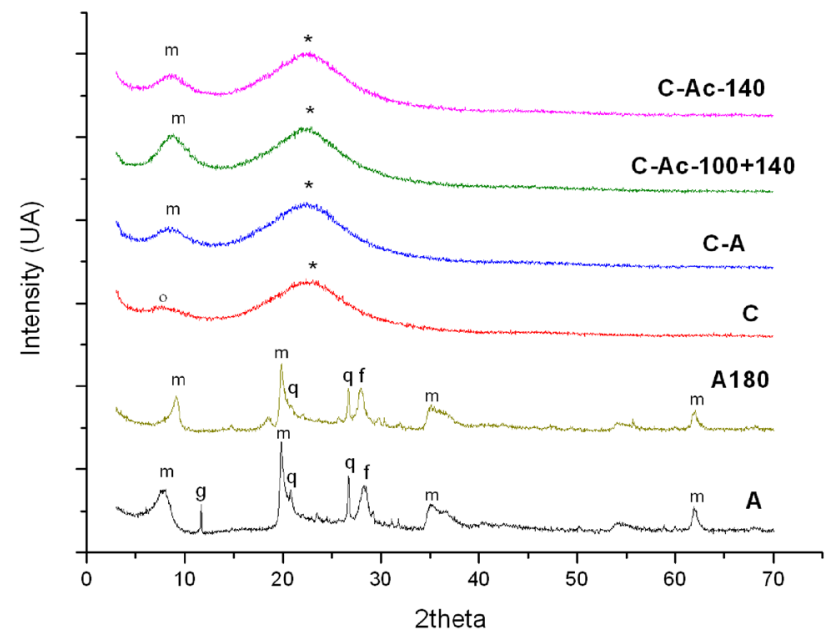

Fig. 1 X-ray Diffractograms of the composites C, C-A, C$A c-100+140, C-A c-140, A$ and A180, m:montmorillonite, q: quartz, f: feldespar, g: gypsum, o: carbonaceous band and $*$ : siliceous band
C, the first band at $7.52 \theta(11.8 \AA)$ is attributed to organic carbonaceous compounds corresponding to the resin and the second at $23.02 \theta$ to the amorphous siliceous compounds from the TEOS. A difference is observed between $C$ and the other composites within the first band, it narrows and moves to $8.82 \theta(10.0 \AA)$, as a result of the addition of bentonite. The presence of montmorillonite in the composites shifts the band to greater angles because of the contraction of the interlamellar spacing product of the interaction of the composite precursors with montmorillonite clusters. In the case of the C-Ac-140 and $C-A c-100+140$, the patterns did not show differences with $C-A$, only the $C-A c-100+140$ presents an increase in crystallinity in the band. The siliceous reflection remains unchanged for all the composites. Due to the low ratio of bentonite in the composites, the corresponding reflections are not displayed in the composites patterns.

\subsection{Differencial thermal and thermogravimetric analyses}

The DTA curves are shown in Fig. 2a., two endothermic peaks are observed in A corresponding to the loss of hydration water at $74.6^{\circ} \mathrm{C}$ and $122^{\circ} \mathrm{C}$ corresponding to gypsum and montmorillonite respectively, while at $657{ }^{\circ} \mathrm{C}$ other endothermic peak is observed corresponding to the dehydroxylation, $\mathrm{OH}^{-}$loss, in the structure of montmorillonite.

Belonging to the composites curves, there are two exothermic wide peaks in the range of $180-500^{\circ} \mathrm{C}$ related to the combustion of organics compounds and also carbon in the composites with carbon added.

In Fig. 2 b the thermogravimetric analyses curves shown a great difference in the mass loss between composite $C$ and the others because the three composites with clay lose at least $10 \%$ more mass. This mass loss occurs in the range mentioned above exhibiting a large process of mass loss being able to overlap two processes. The first would be the completion of the curing of the body and the resin, and then the decomposition of the resin. The difference is attributed to montmorillonite fraction which would interact in the curing processes. In the primary composite, $\mathrm{C}$, both were cured until $180^{\circ} \mathrm{C}$ but in the bentonite composites the functional groups $\mathrm{HO}-\mathrm{Si}(\mathrm{OR})_{3}$ from TEOS and $\mathrm{C}-\mathrm{OH}$ from the aromatic ring would bond in the external surface and in the edges of the montmorillonite, inhibiting and delaying the process [19-21].

Thus, curing extends over $180^{\circ} \mathrm{C}$ because $\mathrm{R}-\mathrm{OH}$ groups are desorbed at higher temperatures, as it is evidenced in the differences of mass loss in Fig. $2 b$.

Comparing only the mass loss between the composites with added carbon, $\mathrm{C}-\mathrm{Ac}-100+140$ presents a greater mass loss than the $\mathrm{C}-\mathrm{Ac}-140$ and this can be attributed 

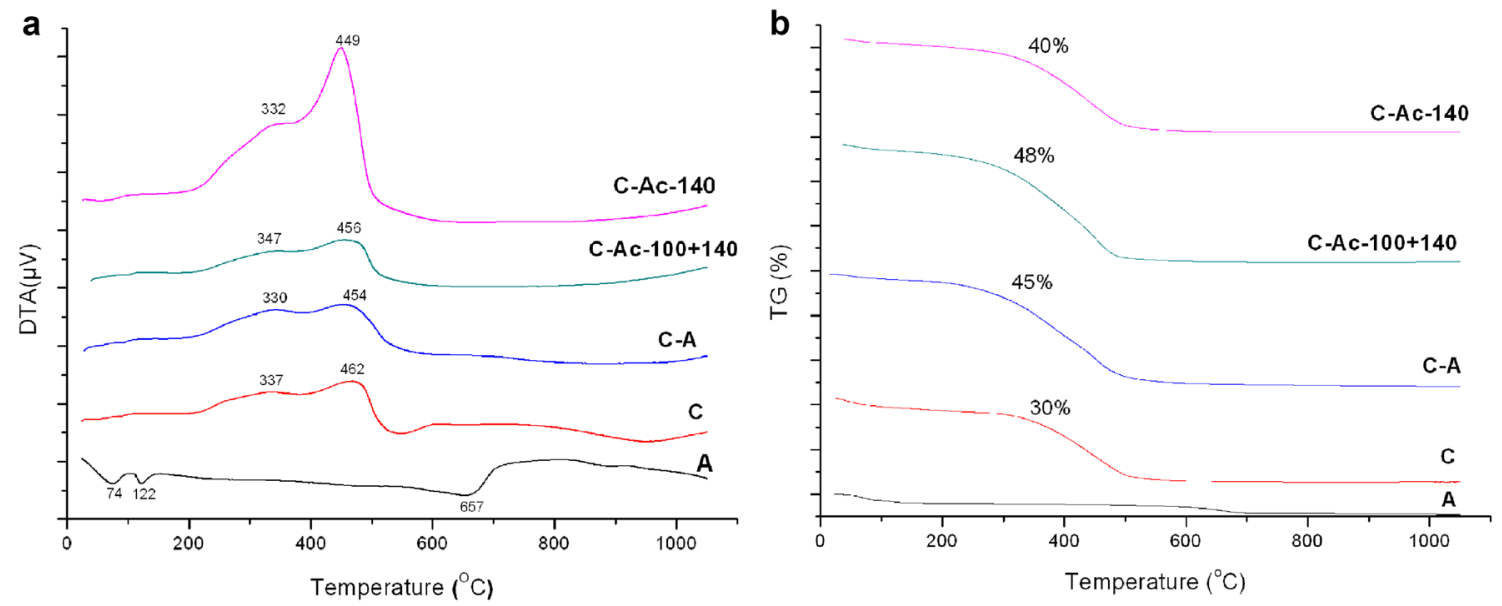

Fig. 2 a Differential thermal analysis curves and $\mathbf{b}$ thermogravimetric analyses curves of the composites $C, C-A, C-A C-100+140, C-A c-140$ and $\mathrm{A}$

to two factors. One is the higher particle size of the carbon added in the $C-A c-100+140$, and because of this it was easily available for combustion. The other is the lower percentage of impurities in the largest fraction being confirmed by lost of ignition at $1000^{\circ} \mathrm{C}$ in both fractions (LOI C $-100+140=2.5 \%$ and LOI- $1-0=5.0 \%)$. Also the differences between the temperatures of the exothermic peaks is given because $\mathrm{O}_{2}$ diffuses more rapidly through the pores of $C-A c-140$, because size of the carbon particle is smaller than C-Ac-100+140, so combustion occurs at lower temperatures than in the case of C-Ac-100+140.

\subsection{FT-IR spectroscopy}

IR Spectras of $A$ and the composites obtained are shown in Fig. 3. In the case of A spectrum is typical of bentonite, a signal at $510 \mathrm{~cm}^{-1}$ corresponding with the stretching deformation ( $\mathrm{SiO}-\mathrm{Al} / \mathrm{Fe} / \mathrm{Mg}), 790 \mathrm{~cm}^{-1}$ related to $\mathrm{Si}-\mathrm{O}$ vibration characteristic of quartz and another at $860 \mathrm{~cm}^{-1}$ of the $\mathrm{Al}-\mathrm{O}$ deformations $920 \mathrm{~cm}^{-1}$ attributed to $\mathrm{Mg}-\mathrm{Al}-\mathrm{OH}$. The signal at $1680 \mathrm{~cm}^{-1}$ correspond to $\mathrm{H}_{2} \mathrm{O}$ deformation (adsorbed between aluminium-silicate layers) and $3438 \mathrm{~cm}^{-1}$ is due to the $\mathrm{H}-\mathrm{OH}$ vibrations of the water adsorbed on the interlayer structure and the band at $3630 \mathrm{~cm}^{-1}$ is attributed to $\mathrm{Al}-\mathrm{OH}$ stretching.

The spectra of the composites are similar between each other, and no significant differences are shown although the effect of a sligth dilution due to bentonite and carbon added. The signal at $752 \mathrm{~cm}^{-1}$, belonged to the $\mathrm{C}-\mathrm{H}$ out of plane vibrations, weak bands derived from stretching vibrations of $\mathrm{CH}$ at $3045 \mathrm{~cm}^{-1}$, the band at $1649 \mathrm{~cm}^{-1}$ is derived from the $\mathrm{C}=\mathrm{C}$ vibration in the aromatic ring, while wave-number $1514 \mathrm{~cm}^{-1}$ is a vibration of $\mathrm{CH}_{2}$ group and also a broad signal at $3450 \mathrm{~cm}^{-1}$ is related to the stretching

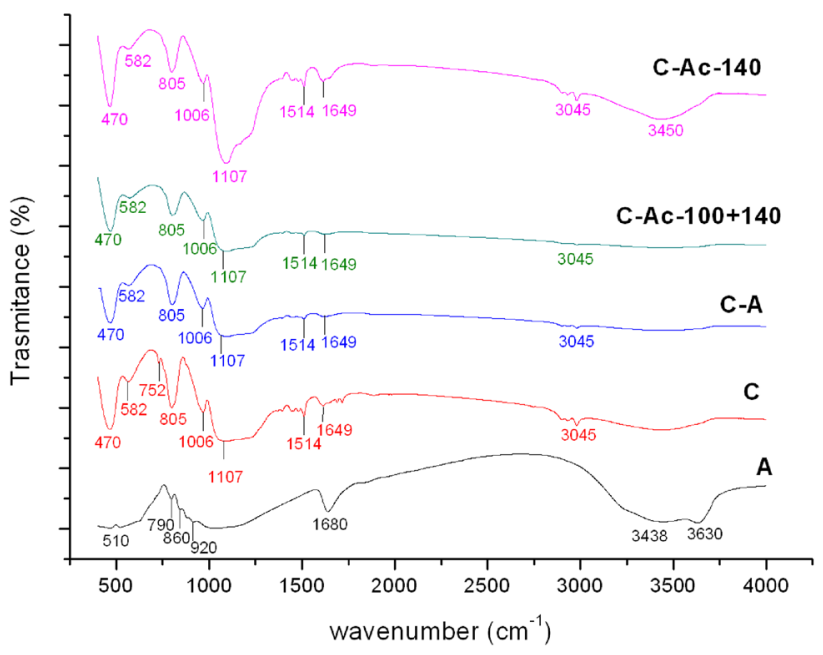

Fig. 3 FTIR spectra of the composites C, C-A, C-AC-100+140, CAc-140 and $A$

vibrations of $\mathrm{OH}$ in the aromatic ring $(\mathrm{C}-\mathrm{OH})$ coming all from the resin. The signals in 470,582, and $805 \mathrm{~cm}^{-1}$ were related to the $\mathrm{Si}-\mathrm{O}-\mathrm{Si}$ unions from condensation of TEOS, a wide signal around $1107 \mathrm{~cm}^{-1}$ assigned to $\mathrm{Si}-\mathrm{O}-\mathrm{R}$ from TEOS but there are other signals inside corresponding to resin groups. A signal at $1006 \mathrm{~cm}^{-1}$ is related with $\mathrm{Si}-\mathrm{O}-\mathrm{C}$ but $\mathrm{Si}-\mathrm{O}-\mathrm{Si}$ also absorbs in this region $[22,23]$.

\subsection{Texture analyses}

The size distribution of pores by the mercury intrusion technique was determined for $A$ and the composites. For this purpose, a non-wetting liquid, mercury, is used to penetrate into the pores of the material while pressure is applied. 

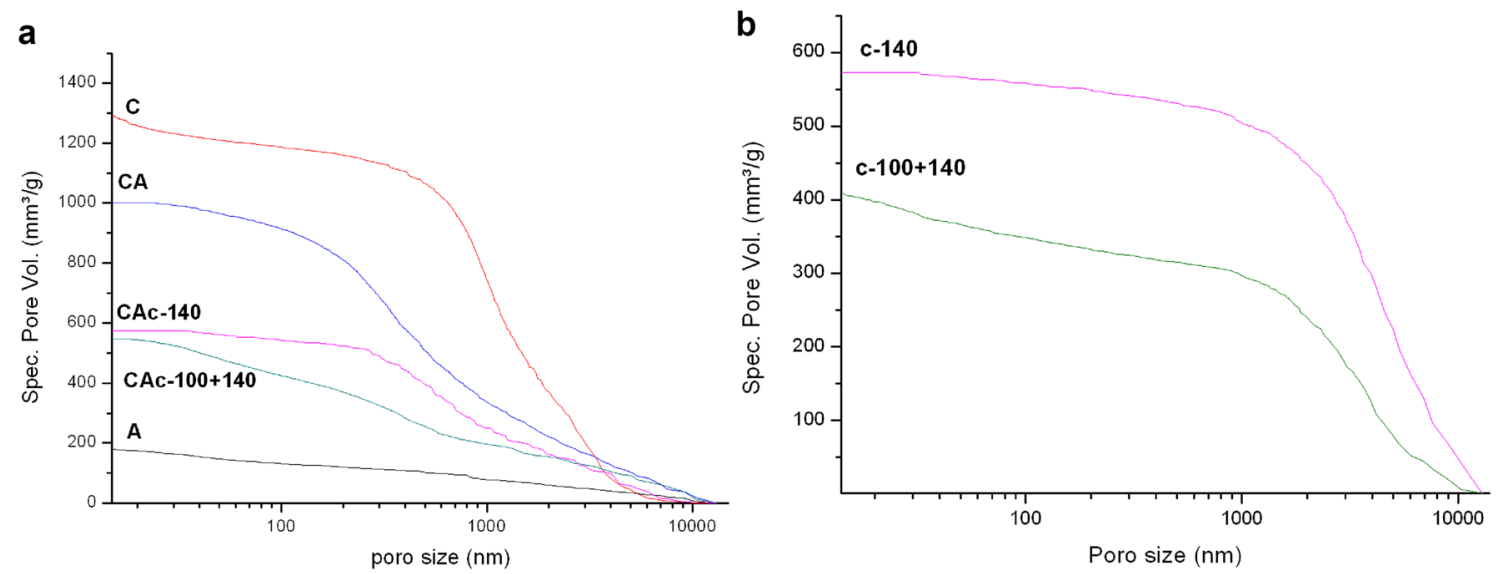

Fig. 4 a Pore size distribution of the composites C, C-A, C-Ac-100+140, C-AC-40 and A. b Pore size distribution of carbon fractions

Sample A presents a continuous range-wide distribution, while carbons (Fig. 4b) in both particle sizes have a similar distribution, which narrows between 2000 and $7000 \mathrm{~nm}$ differing in the maximum pore volume. The $c-100+140$ shows lower total porosity than the $c-140$ because the smaller particle size of the last one exposes more pores (or closed pores were broken). The composite $C$ differs from the others by the narrowest distribution, with the larger average pore diameter $(\sim 1000 \mathrm{~nm})$ and greater total volume (approx. $1200 \mathrm{~mm}^{3} / \mathrm{g}$ ). The composites, C-A, C-Ac-140 and C-Ac-100+140 feature distributions whose average diameter values decrease as well as the total pore volume. The addition of bentonite $(C-A)$ modifies the behavior of the pore size distribution comparing with composite $C$, decreasing the porosity and the average pore diameter $(\sim 400 \mathrm{~nm})$. The composite C-Ac-100 +140 shows less porosity that $C-A c-140$ due to the unexposed porosity in the large particle size of the carbon.

The analyses of the experimental nitrogen isotherms of adsorption-desorption are carried out for $A$ and composites to investigate the texture of the composites surfaces. In Fig. 5 only $\mathrm{C}$ and $\mathrm{C}-\mathrm{A}$ and $\mathrm{A}$ adsorption-desorption curves are shown in order to compare and analyze the differences and due to the behaviours found can be classified as type V [24]. The hysteresis cycle indicates presence of mesopores and the increase of adsorption at high relative pressures suggest the presence of larger pores. As it is known and shown A presents the typical hysteresis cycle of laminar pores as it is with bentonites. The shape of the isotherms $\mathrm{C}-\mathrm{A}$ and $\mathrm{C}$ indicate a narrow type of pore where the interaction of bentonite slightly modify the behaviour of the isotherms. The textural characteristics are present in Table 2.

Composite $C$ presents the highest value of specific surface being $27.8 \mathrm{~m}^{2} / \mathrm{g}$, while the addition of bentonite

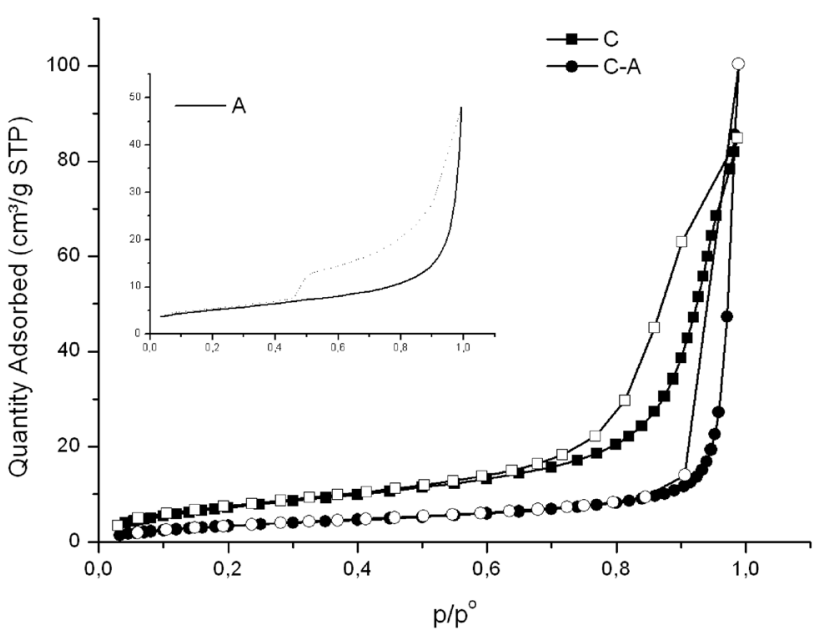

Fig. 5 Adsorption-desorption isotherms of $\mathrm{C}$ and $\mathrm{C}-\mathrm{A}$ and $\mathrm{A}$

Table 2 Textural characteristic determined by adsorption of $\mathrm{N}_{2}$ of the composites and $A$

\begin{tabular}{llll}
\hline Composite & S BET $\left(\mathrm{m}^{2} / \mathrm{g}\right)$ & $\mathrm{Dm}(\mathrm{nm})$ & $\mathrm{Vt}\left(\mathrm{cm}^{3} / \mathrm{g}\right)$ \\
\hline A & 18.1 & 13.2 & 0.07 \\
C & 27.8 & 18.2 & 0.13 \\
C-A & 13.7 & 38.6 & 0.15 \\
C-Ac-140 & 11.8 & 32.5 & 0.10 \\
C-Ac-100+140 & 4.3 & 15.3 & 0.023 \\
\hline
\end{tabular}

generates a decrease in the evaluation of the specific surface area. Although the specific surface decrease in C-A, the pore volume and the mean pore diameter increase from C. In accordance with what is observed in Fig. 4, the type and size of pore in C-A modifies due to the addition of bentonite. It increase the pore size of mesopores and decrease the pore size of macropores what would improve 
the interaction and adsorption of contaminant molecules from aqueous medium. The composite $\mathrm{C}-\mathrm{Ac}-140$ and C-Ac-100+140 evidenced lower values of specific surface following the same ratio observed for mercury porosity determined, that a greater carbon particle size has less values of exposed surface due to the existence of closed pores. Even though the addition of carbon presents a decrease in all the values.

\subsection{SEM analyses}

In Fig. $6 a, b, c, d$ and e the electronic microphotographys of bentonite and the composites are shown. In the case of $A$ (Fig. 6a) the characteristic lamellar structure of a bentonite was observed.

In the microphotography of $\mathrm{C}$ (Fig. $6 \mathrm{~b}$ ) it is seen the structure of the sponge type of the composite, also spheres with the sponge texture of composite, and others smooth (EDS analysis indicates mostly silica) showing that condensation process was carried out. In addition, some zones of the composite can be observed a concentration of hollow spheres which may be due to the evaporation of $\mathrm{ROH}$ groups during the process of drying.

Figure $6 c$ shows a similar structure to $C$, mostly shown the spongy structure of the composite, bentonite and hollow spheres, but not so frecuently seen closed spheres of silica. The C-Ac-100+140 (Fig. 6d) microphotography clearly shows the presence of carbon, with its particular structure in the form of honeycomb. As in the previous composites, it is also observed the spongy structure of the composite, bentonite and hollow spheres. The C-Ac-140 (Fig. 6e) microphotography evidence only one difference with the previous composite and it is the presence of carbon in a smaller size.
Fig. 6 a-e Microphotography of $A, C, C-A, C-A C-100+140$ and $\mathrm{C}-\mathrm{AC}-140$
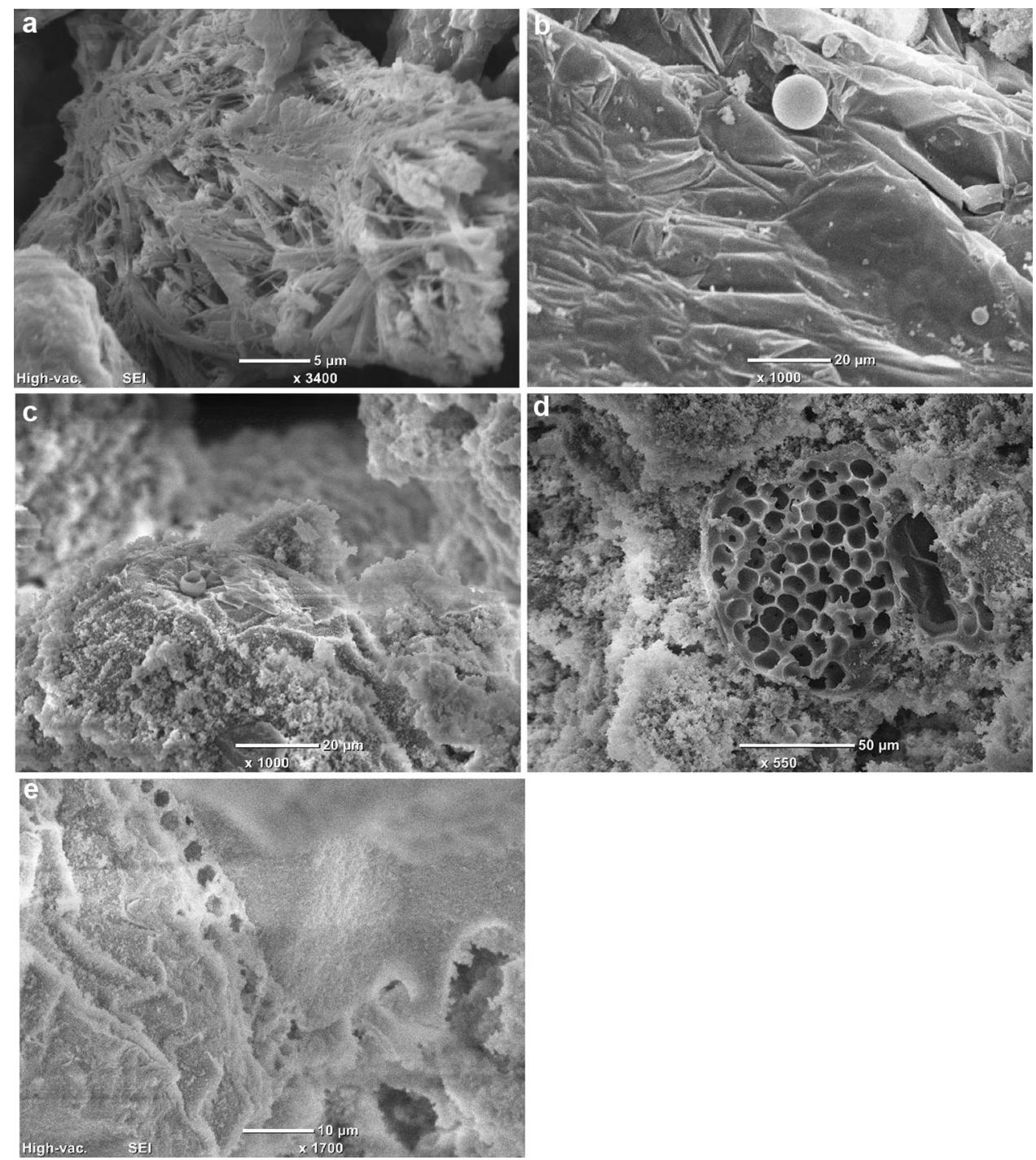


\section{Conclusion}

The composites developed, C, C-A, C-Ac-100+140 and C-Ac-140 differ in the addition of bentonite and carbon. The content of bentonite in the composite was the maximum rate of bentonite-resin-TEOS allowed to obtain an homogeneous material, because of the swelling capacity of bentonite.

Different techniques of characterization were applied to understand the effect caused by the addition of bentonite and carbon. It was found that the addition of bentonite to the sol-gel process composite obtention interferes in the curing process. The functional groups $\mathrm{HO}-\mathrm{Si}(\mathrm{OR})_{3}$ from TEOS and $\mathrm{C}-\mathrm{OH}$ from the aromatic ring of the resin, interact/bond on the external surface and the edges of the montmorillonite, limiting the composite cured. This generates lower macroporosity comparing with the primary composite $\mathrm{C}$ and higher mesoporosity.

The addition of carbon decreases even more the macro and meso porosity of the composite, being the lowest the largest carbon particle size because of the unexposed pores.

This preliminar preparation and characterization of these composites allow us to advance in the development of an adsorbent material for contaminants in aqueous medium.

\section{Compliance with ethical standards}

Conflict of interest Mrs. Maria Celeste Legarto on behalf of all authors, the corresponding author states that there is no conflict of interest.

\section{References}

1. Newman A (1987) Chemistry of clays and minerals, vol 480. Longman Scientific \& Techmical, Mineralogical Society

2. Bergaya F, Lagaly G (2006) General introduction: clays, clay minerals, and clay science. Dev Clay Sci 1:1-18

3. Bergaya F, Lagaly G (2013) Handbook of clay science, 2nd edn. Elsevier, Amsterdam

4. Lagaly G (2001) Pesticide-clay interactions and formulations. Appl Clay Sci 18:205-209

5. Azarkan S, Peña A, Draoui K, Sainz-Diaz Cl (2016) Adsorption of two fungicides on natural clays of Morocco. Appl Clay Sci 123:37-46

6. Zhu R, Chen Q, Zhou Q, Xi Y, Zhu J, He H (2016) Adsorbents based on montmorillonite for contaminant removal from water: a review. Appl Clay Sci 123:239-258
7. Lombardi B, Eloy P, Genet M, Torres Sánchez RM (2006) Interaction of thiabendazole and benzimidazole with montmorillonite. Appl Clay Sci 33:59-65

8. Lombardi B, Baschini M, Torres Sánchez RM (2003) Optimisation of parameters and adsorption mechanism of thiabendazole fungicide by a montmorillonite of North Patagonia, Argentine. Appl Clay Sci 24:43-50

9. Lombardi B, Baschini M, Torres Sánchez R (2003) Retention of the fungicide, thiabendazole in montmorillonites of the Northern Patagonia Argentina. In: Herkovitz (ed.) Proceeding of toxicology and environmental chemistry, contribution to sustainable development, Buenos Aires, pp. 101-103

10. Rashed M (2013) Adsorption technique for the removal of organic pollutants from water and wastewater. In: Organic pollutants-monitoring, risk and treatment. Chapter 4. INTEC Open

11. Moreno-Castilla C (2004) Adsorption of organic molecules from aqueous solutions on carbon materials. Carbon 42:83-94

12. Putraa E (2009) Performance of activated carbon and bentonite for adsorption of amoxicillin from wastewater: Mechanisms, isotherms and kinetics. Water Res 43:2419-2430

13. Meera K, Sankar R, Murali A, Jaisankar N (2012) Sol-gel network silica/modified montmorillonite clay hibrid nanocomposites for hydrophobic surface coatings. Colloids Surf B 90:204-210

14. Scian A, Volzone $\mathrm{C}$ (2001) Novel $\mathrm{SiO}_{2} \mathrm{C}$ composite material. Boletín Sociedad Española de Cerámica y vidrio 40:279-284

15. Yu X, Ding S, Meng Z, Liu J, Qu X, Lu Y, Yang Z (2008) Aerosol assisted synthesis of silica/phenolic resin composite mesoporous hollow spheres. Coll Polym Sci 286:1361-1368

16. Lombardi B, Baschini M, Torres Sánchez R (2002) Characterization of montmorillonite from North Patagonia (Argentina) deposits: physicochemical and structural parameters correlation. J Arg Chem Soc 90:87-99

17. Lombardi B, Baschini M, Torres Sánchez R (2003) Bentonite deposits of Northern Patagonia. Appl Clay Sci 22:1-4

18. Brown G, Brindley W (1980) Crystal structure of clay minerals and their X-ray identification, vol 5. The Mineralogical Society of Great Britain and Ireland

19. Qian Z, Hu G, Zhang S, Yang M (2008) Preparation and characterization of montmorillonite-silica nanocomposites: a sol-gel approach to modifying clay surfaces. Phys B 403:3231-3238

20. Carrado A (2000) Synthetic body- and polymer-clays: preparation, characterization, materials and applications. Appl Clay Sci 17:1

21. Carrado A, Xu L, Csencsits R, Muntean V (2001) Use of organ-and alkoxysilanes in the synthesis of grafted and pristine clays. Chem Mater 13:3766-3773

22. Sócrates $\mathrm{G}$ (2011) Infrared and Raman characteristics group frequencies, 3rd edn. Wiley, Chichester

23. Farmer V (1974) Infrared spectras of minerals. The Minerological Society, London

24. Sing K, Everett D, Haul R, Moscou L, Pierotti R, Rouquerol J, Siemieniewska T (1985) Reporting physisorption data for gas/solid system. Pure Appl Chem 57(4):603-619

Publisher's Note Springer Nature remains neutral with regard to jurisdictional claims in published maps and institutional affiliations. 